\title{
Care Taking of Obstetric Emergencies in the Department of Gynaecology and Obstetrics at Donka National Hospital, University Teaching Hospital (CHU) of Conakry, Guinea
}

\author{
Boubacar Siddi Diallo1* ${ }^{*}$ Ibrahima Sory Balde², Ibrahima Conte' ${ }^{2}$ Mamadou Hady Diallo1, \\ Ousmane Balde', Ibrahima Sylla ${ }^{2}$, Abdourahmane Diallo², Oumou Hawa Bah', \\ Fatoumata Binta Sow ${ }^{1}$, Telly Sy$^{2}$, Yolande Hyjazi ${ }^{1}$, Namory Keita ${ }^{1}$ \\ ${ }^{1}$ University Department of Gynecology-Obstetrics, Donka National Hospital, Conakry, Guinea \\ ${ }^{2}$ University Department of Gynecology-Obstetrics, Ignace Deen National Hospital, Conakry, Guinea \\ Email: *tounty1@yahoo.fr, baldeisory@yahoo.fr, conteib1976@gmail.com, hadydiallo@yahoo.fr, baldeousmane04@gmail.com, \\ dribra62@yahoo.fr, adiallo69gn@yahoo.fr, camarahawa2002@gmail.com,sow52005@gmail.com, sytelly@yahoo.fr, \\ namoryk2010@yahoo.fr
}

How to cite this paper: Diallo, B.S., Balde, I.S., Conte, I., Diallo, M.H., Balde, O., Sylla, I., Diallo, A., Bah, O.H., Sow, F.B., Sy, T., Hyjazi, Y. and Keita, N. (2019) Care Taking of Obstetric Emergencies in the Department of Gynaecology and Obstetrics at Donka National Hospital, University Teaching Hospital (CHU) of Conakry, Guinea. Open Journal of Obstetrics and Gynecology, 9, 604-611.

https://doi.org/10.4236/ojog.2019.95059

Received: March 21, 2019

Accepted: May 10, 2019

Published: May 13, 2019

Copyright $\odot 2019$ by author(s) and Scientific Research Publishing Inc. This work is licensed under the Creative Commons Attribution International License (CC BY 4.0).

http://creativecommons.org/licenses/by/4.0/

\section{(c) (i) Open Access}

\begin{abstract}
Objectives: The objectives of this work were to calculate the frequency of obstetrical emergencies, to describe the socio-demographic profile of women admitted for obstetric emergencies, to identify the main emergencies, to describe the care taking of emergencies and to establish the maternal foetal prognosis of obstetric emergencies. Methodology: It was a 6-month descriptive prospective study conducted in the Obstetrics and Gynaecology Department of the Donka National Hospital, CHU Conakry, Guinea. The study took place from July 1st to December 31st, 2005. The data collected were entered and corrected using the Word and Excel 2010 software and then transferred to the Epi Info software version 7 for analysis. The results are presented in the form of tables, figures and texts using Word and Excel software, commented on, discussed and compared to current literature data. The limitations of the study: The poor filling of the partograph has been the main problem of our study. Results: The frequency of obstetric emergencies was 19\% in the Department. The socio-demographic profile was that of a woman aged 15 to 24 (46.4\%), married (92\%), housewives (38.1\%), out of school (49.5\%), nulliparous (34.3\%), without prenatal follow-up (47.37\%), coming from home (56\%), evacuated (44\%). The main emergencies are dominated by haemorrhage (34.5\%) followed by HTA Arterial hypertension and eclampsia (25.7\%). The therapeutic attitude was based on clinical data and was dominated by
\end{abstract}


caesarean section (70\%). General anaesthesia was performed in $75 \%$ of cases and $1.6 \%$ benefited from local anaesthesia. The demand for blood was honoured in $19 \%$ of the cases. The maternal morbidity was dominated by anaemia $(66.7 \%)$ and a lethality of $4 \%$. After the 5 th minute, $47 \%$ of the newborns had APGAR greater than 7 . The neonatal mortality rate was $21 \%$. Conclusion: To avoid and/or reduce obstetric emergencies, it is necessary to detect and treat risk factors during referrals, properly monitor child labor, refurbish providers of basic facilities, promptness in the management of the admission of emergencies and the availability of blood products.

\section{Keywords}

Obstetric Emergency, Care Taking

\section{Introduction}

Obstetric emergencies are accidents that occur suddenly during pregnancy and in the aftermath of diapers exposing women to serious risks and whose evolution is sometimes fatal [1].

The most common complications are: haemorrhage, dystocia, SFA (sharp fetal suffering), eclampsia and pre-eclampsia.

However, safe motherhood remains the major challenge for any action to improve maternal and child health [2].

Obstetric emergencies are common in developing countries.

In Benin in 2013, at the University Hospital of Parakou, obstetric emergencies accounted for $31.8 \%$ with a maternal lethality of $0.4 \%$ and a foetal rate of $9.2 \%$ [3].

In Mali in 2007, 12.24\% of obstetric emergencies are at the reference health centre of the commune IV with a maternal lethality of $1 \%$ and foetal mortality of 23.9\% [4]. And in the same country in the health district of Nara/Koulikoro Region in 2009 , obstetric emergencies represented $23.52 \%$ with a foetal lethality of $18 \%[5]$.

In Guinea, at the Labe Regional Hospital in 2013, obstetric emergencies represented $14.75 \%$ with a maternal lethality of $2.5 \%$ and foetal malnutrition of $3 \%$ [6].

Thus, we conducted this study with the objectives of calculating the frequency of obstetric emergencies, describing the socio-demographic profile of women admitted for obstetric emergencies, identifying the main emergencies, describing the management of emergencies and establishing the maternal-foetal prognosis of obstetric emergencies.

\section{Methodology}

It was a 6-month descriptive prospective study conducted at the maternity of the 
DONKA National Hospital, which is a $3^{\text {rd }}$ level referral facility in Guinea.

The study focused on a continuous series of 633 obstetric emergencies. All patients admitted for an obstetric emergency in the Department were included in the study. Patients who died on admission, patients with no obstetric emergencies and those who did not consent to the study were excluded from the study.

The study took place from July 1st to December 31st, 2005.

The data collected were entered and corrected using the Word and Excel 2010 software and then transferred to the Epi Info software version 7 for analysis. The results are presented in the form of tables, figures and texts using Word and Excel software, commented on, discussed and compared to current literature data.

The limitations of the study: The poor filling of the partograph has been the main problem of our study.

The variables studied were: epidemiological, clinical, para-clinical, therapeutic and prognostic.

\section{Results}

\subsection{Frequency}

During our study period we recorded 633 obstetric emergencies for a total of 3396 admissions, equivalent to a frequency of $19 \%$.

\subsection{Socio-Demographic Profile}

1) Age. The age group of 15 to 24 is the most concerned $(45.8 \%)(n=290)$ with an average age of 25.38 years and extremes of 14 and 44 years.

2) Profession: Housewives were the most met (38.1\%).

3) Level of education: The majority of our patients were illiterate $49.5 \%$.

4) Matrimonial status: Married women accounted for $91.6 \%$ of patients.

\subsection{Clinic and Para-Clinic}

1) Admission Mode: 353 patients came directly from their home (56\%) and 280 were evacuated or referred by the other health structures (44\%).

2) Evacuation reasons:

Evacuated patients were admitted without evacuation papers (49.64\%), while $21.42 \%$ of patients were discharged for HTA and eclampsia and 7.5\% for HRP.

3) Reasons for consultation: The main emergencies are dominated by bleeding (34.5\%) followed by hypertension and eclampsia (28.6\%).

4) Parity: Nulliparous women represented $34.3 \%$ of our patients followed by pauciparas $26.1 \%$.

5) Prenatal follow-up: Patients without prenatal care accounted for $47.37 \%$.

\subsection{Therapeutics}

The therapeutic attitude was based on clinical data. Caesarean section was performed immediately in $70.6 \%$ of cases, vaginal delivery in $10 \%$ and laparotomy in $4 \%$ of our patients. $19 \%$ of our patients benefited from a blood transfusion. 
General anesthesia was performed in $75 \%$ of our obstetric emergencies and $1.6 \%$ benefited from local anesthesia.

\subsection{Prognosis}

\subsubsection{Maternal Prognosis}

1) Morbidity: $6 \%$ of our patients developed complications during the delivery.

2) Types of maternal complications: These complications are dominated by anemia (66.7\%) followed by infections (33.3\%).

3) Maternal lethality: We recorded 24 cases of maternal deaths, a frequency of $4 \%$ of our obstetric emergencies.

4) Causes of maternal deaths: The main causes of these deaths were hemorrhage $37.5 \%$, followed by eclampsia $20.8 \%$.

\subsubsection{Fetal Surgery}

1) APGAR Score: $60 \%$ of newborns had APGARs between $7-9$ in the $1^{\text {st }}$ minute, while in the $5^{\text {th }}$ minute $47 \%$ had APGARs between 7 - 9 and only $2 \%$ had APGARs between 4 to 6 .

2) Neonatal mortality: 120 cases of fetal death (115 cases of dying born and 5 cases of fetal deaths) were recorded out of a total of $\mathbf{5 7 1}$ births, i.e. a frequency of $21 \%$.

\subsubsection{The Duration of Hospitalization of Patients}

$56.7 \%$ of our obstetric emergencies took between 1 to 4 days of hospitalization while $0.6 \%$ performed between 21 to 24 days of hospitalization.

\section{Discussion of the Findings}

\subsection{Frequency}

We collected 633 cases of obstetric emergencies out of a total of 3396 admissions, i.e. a frequency of $19 \%$. This result is included the one found by CISSE SA [7] in Mali (28.24\%) and TOURE [6] (12.75\%) in Labé (Guinea) in 2013. This high frequency in our study could be explained by the fact that the service constitutes a national reference service.

\subsection{Sociodemographic Profile}

1) Age: The age group 15 to 24 is the most concerned $(45.8 \%)(\mathrm{N}=290)$ with an average age of 25.38 years and extremes of 14 and 44 years. $0.15 \%$ of our patients were under 15 years old. This young age could be explained by the psychological immaturity of young age patients and/or early marriage. GUINDO SB [8] finds in his study that the age group of 20 to 34 years was the most represented (63.8\%) whereas CISSE SA [7] reports that the age group of 25 to 29 years was the most representative (32\%).

2) Profession: Housewives were the most met (38.1\%), similar to TOURE.I [6] (58.5\%) in Labé (Guinea) in 2013.

3) Level of education: The majority of our patients were illiterate $49.5 \%$. This 
rate of women who did not go to school is in line with that of the general population in Guinea, where $74 \%$ of illiterates are women, $85.3 \%$ of whom are women, according to the Guinean DHS4 [9].

4) Matrimonial status: Married people accounted for $91.6 \%$ of patients. This result is superimposed on that found by TOURE.I [6] (96.6\%) in Labé (Guinea) in 2013. This would be linked on one hand to polygamy and on the other hand to the fact that in our regions, marriage is the only legal way to give birth.

\subsection{Clinic and Para-Clinic}

1) Mode of admission: 353 patients came directly from their houses (56\%) and 280 were evacuated or referred to other health facilities (44\%) This result is similar to that of BLAISE A.T. et al., in Benin [3] in 2013 and THIAM O. and COLL [10] in 2011 in Senegal with respectively $48.5 \%$ and $41.2 \%$ of patients evacuated /referred.

2) Evacuation reasons:

Evacuees were admitted without evacuation papers (49.64\%), while $21.42 \%$ of patients were discharged for HTA and eclampsia and $7.5 \%$ for HRP. In his study, CISSE S.A [7] in Mali reported $12.74 \%$ of patients evacuated without evacuation papers, $16.18 \%$ evacuated for eclampsia and pre-eclampsia and $15.69 \%$ for HRP.

3) Reasons for consultation: The main emergencies are dominated by haemorrhage (34.5\%) followed by hypertension and eclampsia (28.6\%). This rate of haemorrhage is lower than that found by TOURE I. [6] in Labé (Guinea) and CISSE SA [7] in Mali with $44.8 \%$ and 35.59\% respectively. This high frequency of haemorrhage is explained by the place of haemorrhage in causes of death.

4) Parity: Nulliparous women represented $34.3 \%$ of our patients followed by pauciparas $26.1 \%$. This result is superior to that found by TOURE I. [6] in Labé (Guinea) with $29.7 \%$ among nulliparas and $25.4 \%$ among pauciparas.

5) Prenatal follow-up: Patients without prenatal care accounted for $47.37 \%$. This result is similar to that found by CISSE SA [7] in Mali, i.e. 45.7\%. WHO has recommended, since 1998, a minimum of 4 CPN during pregnancy. However, it should be noted that the number of prenatal care does not put pregnant women away from complications and deaths but rather the quality of it and especially the period in which they are performed. This high frequency could be explained by the fact that these patients are unaware of the benefits of prenatal care and also for economic and socio-cultural reasons (unwanted pregnancies, low literacy levels).

\subsection{Therapeutics}

The therapeutic attitude was based on clinical data. Caesarean section was performed immediately in $70.6 \%$ of cases, vaginal delivery in $10 \%$ and laparotomy in $4 \%$ of patients. $19 \%$ of our patients received a blood transfusion. General 
anesthesia was performed in $75 \%$ of our obstetric emergencies and $1.6 \%$ benefited from local anesthesia. Our cesarean section rate is intermediate like that found by CISSE SA [7] 73.67\% and those reported by CISSE B [11], GUINDO S.B [8], and TOURE I [6] with respectively $48.2 \% ; 49.22 \%$ and $63.6 \%$. This high proportion of caesareans would be due to the fact that it is the last resort for the obstetrician to help parturients 2 or 3 times evacuated with dynamic failures refractory to medical treatment.

\subsection{Prognosis}

\subsubsection{Maternal Prognosis}

1) Morbidity: $6 \%$ of our patients developed complications during the delivery.

2) Types of maternal complications: These complications are dominated by anemia $(66.7 \%)$ followed by infections (33.3\%) Our anemia rate is intermediate between that found by CISSE B. [11] $86 \%, 5 \%$ and those reported by BALLO B. [12], SALIHOU A. [13] and COULIBALY D [4] with 8.5\%; $22.2 \%$ and $40 \%$.

3) Maternal lethality: We recorded 24 cases of maternal deaths, a frequency of $4 \%$ of our obstetric emergencies. This result is similar to that of GUINDO S.B [8] 3.96\% and lower than those reported by SALIHOU A. [13] and CISSE SA [7] with respectively $6.3 \%$ and $11.03 \%$.

4) Causes of maternal deaths: The main causes of these deaths were hemorrhage $37.5 \%$, followed by eclampsia $20.8 \%$. The finding is similar in the studies of Dellagi RT [14] in Tunisia and Horo [15] in Cote d'Ivoire with lower proportions. However, for Benmouhoud [16] in Algeria in 2011, hemorrhages ranked $2^{\text {nd }}$ with $16.60 \%$.

\subsubsection{Fetal Surgery}

1) APGAR Score: $60 \%$ of newborns had APGARs between 7 - 9 in the 1 st minute, while in the 5 th minute $47 \%$ had APGARs between 7 - 9 and only $2 \%$ had APGARs between 4 to 6.

2) Neonatal Mortality: We recorded 120 cases of fetal deaths (115 cases of dead born and 5 cases of fetal deaths) out of a total of 571 births, a frequency of $21 \%$. These deaths could be explained by the delay in referral or evacuation. Some unforeseeable complications (HRP, PP, UK, SFA) and delay in promptness of emergency care.

\subsubsection{The Duration of Hospitalization of Patients}

$56.7 \%$ of our obstetric emergencies took place between 1 to 4 days of hospitalization while $0.6 \%$ performed between 21 to 24 days of hospitalization. CISSE SA [7] reports $24.56 \%$ of patients who were hospitalized between 5 to 8 days and $1.42 \%$ hospitalized for 16 days or more.

\section{Conclusion}

To avoid and/or reduce obstetric emergencies, it is necessary to identify and 
treat risk factors during referrals, properly monitor childbirth, refurbish providers of basic facilities, readiness for the care taking of the emergencies and the availability of blood products.

\section{Conflicts of Interest}

The authors declare no conflicts of interest regarding the publication of this paper.

\section{References}

[1] Keita, N. (2008) Gynecological and Obstetric Emergencies at the Health Center of Reference of Kolondieba. Thesis Medicine, No. 110, 7-9.

[2] Kouakou, P., Djanhan, Y., Yakouba, D., Djanhan, L. and Ouattara, M. (2007) Uterine Rupture: Epidemiological Aspects and Fœto-Maternal Prognosis at the Maternity Hospital of Bouaké University Hospital, Cote D’Ivoire. CAMES-Series a Review, Vol. 5.

[3] Tchaou, B.A., Hounkponou, N.F.M., Salifou, K., Zoumenou, E. and Chobli, M. (2015) Obstetric Emergencies at the Parakou University Hospital in Benin: Clinical, Therapeutic and Evolutionary Aspects. European Scientific Journal, 11, 1857-1881.

[4] Coulibaly, D. (2008) Epidemiological and Clinical Study of Obstetric Emergencies at the Reference Health Center of Commune IV of the District of Bamako Concerning 293 Cases. Doctoral Thesis in Medicine, University of Bamako, Bamako, 70-73.

[5] Ballo, B. (2010) Obstetric Emergencies in the Nara Health District/Koulikoro Region for 164 Cases. Doctoral Thesis in Medicine, University of Bamako, Bamako, 96-98. https://doi.org/10.1093/med/9780195396713.003.0008

[6] Toure, I. (2013) Obstetric Emergencies: Epidemiological, Clinical and Therapeutic Aspects at the Labé Regional Hospital. Doctoral Thesis in Medicine, Gamal Abdel Nasser University of Conakry, Conakry, No. 23.

[7] Cisse, S.A. (2008) Management and Prognosis of Obstetric Emergencies at the SominDolo Hospital in Mopti about 281 Cases. PhD Thesis in Medicine, University of Bamako, Bamako, 81-93.

[8] Guindo, S.B. (2008) Obstetric Emergencies as Part of the Referral and Counter Referral to the Obstetrics and Gynecology Department of Sikasso Hospital. Doctoral Thesis in Medicine, University of Bamako, Bamako, 49-81.

[9] National Directorate of Statistics (Guinea) (2005) Demographic and Health Survey III (EDS-MICS, 2005). National Statistical Institute Measure, DHS, International ICF Calverton, 1-13.

[10] Thiam, O., Cisse, M.L., MBaye, M., Niang, M.M., Gueye, M., Diouf, A.A., Dièye, S. and Moreau, J.C. (2013) The Issue of Parturients Evacuated in Senegalese Rural Area: Example of the N'Dioum Hospital Center. CAMES Health Review, 1, 67-75.

[11] Cisse, B. (2013) Evaluation of the Reference System/Evacuation of Obstetric Emergencies at CS Markala Ref. Doctoral Thesis in Medicine, University of Bamako, Bamako, 46-63.

[12] Diarra, K.L. (2008) Acute Fetal Suffering in the Obstetrics and Gynecology Department of Gabriel Touré Teaching Hospital in Bamako. Doctoral Thesis in Medicine, University of Bamako, Bamako, 77 p.

[13] Salihou, A. (2009) Assessments of the Reference System Evacuation of Obstetric 
Emergencies at the Niafunké Reference Health Center from January 2007 to December 2008. Doctoral Thesis in Medicine, University of Bamako, Bamako, 78-81.

[14] Dellagi, R.T., Belgacem, M., Hamrouni, M. and Zouari, B. (2008) Evaluation of the Maternal Death Tracking System in Public Structures in Tunis (1999-2004). Eastern Mediterranean Health Journal, 14, 1-11.

[15] Horo, A.G., Toure-Ecra, F., Mohamed, F., Adjoussou, S. and Koné, M. (2008) Malfunctioning and Maternal Mortality: Analysis of 35 Cases at the Maternity Hospital of Yopougon University Hospital (Abidjan, Ivory Coast). Black Afrique Medicine, 55, 449-453.

[16] Benmouhoud, N. (2010) Maternal Mortality in Algeria. Maghrebian Journal of Anesthesia Punishment and Emergency Medicine, 17, 225-227. 